\title{
FARKLI EKOLLERDE METIN, SÖYLEM VE HIPERMETIN KAVRAMLARI
}

\author{
Doç. Dr. Nurida Samed Kızı NOVRUZOVA ${ }^{1}$
}

\begin{abstract}
ÖZET
Metin, söylem, hipermetin terimleri ve onların ifade ettikleri anlamlar dilbilimde bazen farklı yorumlanmaktadır. Bilim insanları bu kavramların hem benzer hem de farklı kullanımlarını tespit etmektedirler. Makalede Avrupa ve Rus dilbilimcilerinin bu kavramlara yaklaşımları ele alınmaktadır. Dilbilim literatüründe 'metin' ve 'söylem' terimlerinin bazen eş anlam, bazen ise zıt anlamları ifade eden terimler gibi kullanıldığı görülmektedir. Söylem bazen metnin kendisi, bazen ise metnin özel bir şekli gibi kabul edilmektedir. Hipermetin fenomeni ise bilgi aktarımının farklı bir şekli olup, özellikle internetle birlikte bilginin iletilmesi ve yorumlanması olarak görülmektedir.
\end{abstract}

Anahtar Kelimeler: Metin, Söylem, Hipermetin, Total Dil, İntermetin

${ }^{1}$ Bakü Slavyan Üniversitesi, Filoloji Fakültesi, Türkoloji Bölümü, n.nurida@yahoo.com 


\title{
TEXT, DISCOURSE AND HYPERTEXT ACCORDING TO DIFFERENT APPROACHES
}

\begin{abstract}
In the article the terms text, discourse and hypertext, and their meanings are compared, their common and different sides are shown, and the approaches of European and Russian linguists to this issue are compared. It is shown that in the linguistic literature the terms text and discourse are sometimes used as synonymous, as well as terms with different meanings. In some cases discourse can be equal to the text; sometimes it can be a special part of the text. Hypertext, as a new way of delivering the information and as a special text form, was formed to deliver and comment the information from the Internet.
\end{abstract}

Keywords: text, discourse, hypertext, totalitarian language, intertext. 


\section{Giriş}

Metnin oluşturulması, kullanılması ve iletişim sistemindeki temel rolü gündeme geldiğinde söylem ve hipermetin terimleri ayrı bir önem kazanıyor. Buna bağlı olarak söylem ve metin terimlerinin kullanım alanlarının tespiti zorunlu hale geliyor. Bu kavramları birbiriyle kıyaslamak için ve onların farklı-benzer anlamlarını belirlemek için dilbilimdeki mevcut durumlarını saptamaya çalışalım.

Metin ve söylem terimleri dilbilimde farklı açılardan izah edilir. Bazı dilbilimcilerce söylem bir nutuk (verbal, akustik, jest-mimik, mekan) davranışıdır (Mixalskaya, 1996: 46). Dilin araştırılmasının toplumsal politik açıları düşünüldüğünde, "söylem” terimi zihinsel dünyanın, dünya görüşü universumunun simgesi olarak kullanılır.

\subsection{Soruna değişik yaklaşımlar.}

XX.yüzyılın 70'li yıllarında Avrupa dilbilimindeki “söylem” (fr.discours) terimi nutkun (dilin) fonksiyonel uslup anlayışına yakın anlamlarda kullanılırken, Rus dilbiliminde geleneksel olarak söylem, metnin özel bir şeklini belirtmek için kullanılmakta ve uslup bilimi çerçevesinde incelenmekteydi. Daha sonraları Avrupa dilbiliminde "söylem"in, sadece metnin kendisini değil, aynı zamanda metnin arkasında bulunan bir sistemi ve her şeyden önce grameri işaret ettiği görüldü. Söylemi, V.Borbotko, V.Nikolayeva gibi bilim insanlarınca çeşitli şekillerde tanımlanmıştır (Borbotko, 2001: 458-461).

Türkoloji geleneğinden gelen dilbiliminde -ve Azerbaycan dilbiliminde demetin ve söylem terimleri birbirine yakın hatta eş anlamlı terimler olarak kullanılmıştır. Metin dilbilimin önemli araştırmacılardan Tatar dilbilimci $M$. Zekiyev, bu kavramlar için mikrometin veya- "sentaktik bütünler" terimini kullanmanın daha doğru olacağını kabul ediyor ve metnin temel niteliği olarak anlamca, bağca (komünikasyon), yap1 ve gramer açısından bir bütün olması gerektiğinin özellikle altını çizmektedir (Zakiyev, 2008: 340-352).

Prof. K. Abdullayev ise dilbilim literatüründe mikrometnin yanısıra diğer terimlerin de kullanıldığını ve bu terimlerin aynı anlama geldiğini belirtiyor: "dilbilim literatüründe mikrometinle beraber, aynı olayın bilimsel adı olarak 'tekst', 'bileşik sentaktik bütün', 'period', 'söylem', 'paragraf', 'cümlefevki birim' ve diğer sentaktik terimler de kullanılmaktadır. Bu terimlerin neredeyse hepsi genetik bakımdan yakın anlayışları ifade ederler ve birbirlerinin yerine geçebilirler" (Abdullayev, 1999: 180). Lakin yazarın doğru tespit ettiği kadarıyla, 'buna rağmen 
onların bazılarını anlam farklılıklarından dolayı ayırmak lazım', (Abdullayev, 1999: 180).

Azerbaycan dilbiliminde de XX. yüzyılın sonlarına kadar mevcut araştımalarda metin ve söylem genelde eş anlamlı terimler olarak kullanılmıştır. (Novruzova, 2002: 5-17; Ә.Cavadov 1977: 66; Ә. Xəilov, 1967; A.Məmmədov, 2001; Abdullayev, 1999).

Türkiye dilbiliminde de metnin önemli araştımacılarından olan Doğan Günay metin ve söylem terimlerini eş anlamlı olarak kullanmış ve metnin temel özelliklerini metinde tutarlılık (koherentlik), metincilik (metin tekniği) bağdaşlılık (bağlılık) olarak göstermiştir (Günay, 2007: 45). Metindeki cümlelerin metin dışında da olabileceğini kabul eden yazar bunun metnin iç kurallarına bağlı olduğu düşüncesindedir (Günay, 2007: 47). Metnin belli bir hacme, ölçüye sahip olduğunu ve cümleler grubunun metin olarak değerlendirilmesinin onun uzunluğu ya da hacmiyle ilgili olmadığını söyleyen yazar, cümleler birliğinin metin olması için belirli bir özellik, bağlılık, tutarlılık kazanmasının önemini mutlak kabul etmektedir (Günay, 2007: 47).

Rus dilbiliminde söylem; durum ve dildışı faktörlerle birlikte, aynı zamanda medeniyetler arası ilişkiler aracılığıyla güncelleşmiş metin şekli olarak görülmektedir. Bazı dilbilimciler "söylem" terimiyle dil sistemindeki kullanım sürecini anlatırken, diğerleri bu kullanımın sonucunu anlatıyor. Bazılarıysa söylemin "faaliyet" özelliğinin önemli olduğunu vurgulayarak ve onun etimolojik anlamını(sohbet, konuşma, tartışma) kullanmayı daha doğru buluyor (Nikolayeva, 1978; Sorokin, 1985; Kibrik, 2003; Mixaylov, 2006). Hatta Rus dilbiliminde "bilimsel söylem”, "bedii söylem”, “doğal söylem” ifadeleri kullanılır. Bütün bunlar iletişimin amacına göre sınıflandırılır. Günlük konuşma esnasında kullanılan dil sisteminde doğal söylem, bilimsel eserlerin incelenmesinde bilimsel söylem, faaliyetin bedii ifadesi sırasında ise bedii söylem kullanıyoruz.

\section{2. "Totaliter" veya "siyasal söylem" anlayışı}

XX. asrın 70-80'li yıllarının sonlarında "metin" ve "söylem" kavramlarının tedricen ayrılmasının ardından onları birbirinden farklı değerlendirme geleneği ortaya çıktı. "Metin" denildiği zaman genelde soyut, formal yapı, "söylem" denildiği zaman ise zihinsel süreçler açısından ekstralingvistik (dildışı) etkenlere bağlı olarak gözden geçirilen, metnin güncelleştirilmesinin değişik çeşitleri anlaşılmaktadır ( Kupina 1995 : 137). 
Günümüzde "söylem" terimi daha ziyade politik söylemlerin (tartışma, söyleşi) öğrenimi sırasında kullanılıyor. Avrupa ve Rus dilbiliminde geleneksel olarak belirli bir siyasal ideolojinin ifadesi olan metinler söylem olarak kabul edilir. $\mathrm{Bu}$ siyasal söylemler ve ideloji sözcükleri dilbilimde "totaliter dil" kategorisinin oluşmasına neden olmuştur. N.A. Kupina sözlükte yazılmış ideologemleri yeni totalitar tipli bilinçle şekillenen, genelleşmiş alıcı tipine yönelmiş hipermetin olarak kabul ediyor. Yazar bu anlayışın anlamını şöyle açıklıyor: "Hipermetin, geçici ve bölgesel olarak kısıtlanmış, içerik ve situatif olarak birleşen, tam modal gösterişle, yollayıcının ve alıcının yeterince belirlenmiş konumlarıyla, normal ve anormal olanın belirli ölçütleriyle seciyelenen söylemlerin, metinlerin toplamıdır. Bu tür üstün metin kategorisel bir özelliğe sahiptir. (Kupina 1995 :53).

N.A. Kupina’nın düşüncelerine göre Sovyet döneminin-totalitarizim döneminin ideologemlerinin hipermetni tam bütünden ibarettir. Kategorik açıdan bütünlük idiolomonizimle, bakış açılarının modal göstericilerinin tamamlanmasıyla sağlanır. İletişimsel çerçevenin özelliğine göre söylemi ideologemlerin-hipermetnin tek çizgide seyreden, bildirimsel, yazar bakış açısı olan üstünmetni olarak kabul edebiliriz (Kupina 1995: 56). Arutünova ve bazı dilbilimcilere göreyse söylem; "ekstralingvistik-pragmatik, sosyokültürel, psikolojik ve diğer etkenlerle beraber bağlantılı metindir; amaca yönelik sosyal etki gibi görülen nutuktur; insanların karşılıklı ilişkilerinde ve onların bilinç mekanizmalarında (bilişsel süreçlerde) rol alan taraftır"

(Arutünova, 1990: 5-32). Bir başka deyişle "söylem hayata yüklenmiş" nutuktur ve bu yüzden de "söylem" terimi metin teriminden farklı olarak canlı hayatla direkt ilişkisi olmayan eski ve diğer metinlere uygulanamamaktadır (Arutünova, 1990: 136-137).

Söylemin metnin kendisi sayılıp sayılamayacağıyla ilgili tartışmalar her dönem devam etmiştir. Metin ve söylemle ilgili iki temel yaklaşım vardır.

1) Söylem metnin özel halidir;

2) Metin söylemin birimidir.

Metin dilbilim alanında uzman olan S.İ Gindin kesin şekilde söylem terimini inkar ediyor. Ancak, o devirde karşıt görüşlere de rastlamak mümkündür. Örneğin söylem alanında uzman olan V.G.Borbotko bağlantılı nutuk metni için "metin" teriminin değil de "söylem" teriminin kullanılmasını tercih etmiştir. Çünkü dilbilimci için metin terimi işaretlerin istenilen sırasını, aynı zamanda tecrit olunmuş kelimelerin takımını belirtir (Borbotko, 2001: 458-461). Lakin metinle ilgili 
araştırmalar söylemden daha fazladır. Metne yönelik bu dikkatin sebebi, metnin nutuk iletişiminin gerçek birimi olarak gözden geçirilmesidir. Zira son yıllarda sentaksın (cümlebilgisi) "kahramanı" metin olmuştur (Sovremennıy russkiy yazık, 1995: 32). XX. yüzyılın 70’li yıllarında Q.A. Zolotova şöyle yazıyordu: "Son devirlerde dünya dilbiliminde araştıma konusu olarak metin ilk sırayı almıştır. Metin en önemli dilbilim kategorisi olarak nüfuz kazanmaktadır, çünkü dil sisteminde iletişim, tecrit cümlelerle değil çeşitli yapıda ve amaçlı metinlerle gerçekleştirilir" (Zolotova, 1979 :3).

\section{Lingvopoetik paradigmada metin ve söylem kavramı}

Her iki terim de (metin ve söylem) metin dilbiliminciliğinde/söylem teorisinde yaygın kullanılır. Fakat lingvoritopik paradigma çerçevesinde bu terimler daha kesin farklandırılır. Bizce "metin" ve "söylem" anlayışları statik ve dinamik söylemin iki dairesine uygulanabilir. Eğer metnin tahlili söylemin, metnin elokutif katının paradigması ve sintagmatikasının işaretlenmesi sonucunun araştırılmasından oluşuyorsa, o zaman söylemin tahlil süreci gibi düşünülen dildışı etkenlerle beraber metne başvurulmasını gerektirir.

Bilimsel literatürde anlatılan metin modelleri-statik-yap1 (R. Xarveq, T. Van Deyk) ve dinamik-strateji( V.V. Vinaqradov, K. F. Taranovski, Y M. Lotman, Y. N. Karaulov, Z. Y. Turayeva) diye ayrılır. Z.Y.Tugayeva'ya göre metnin araştırılmasında statik modeller için temel istikamet metnin sintagmatikası, dinamikler için ise metnin paradigmasıdır. (Tuqayeva, 1993: 93).

Bu durumda aynı zamanda paradigmatikanın iki tipini- "somut" ve "soyut" tiplerini dikkate almak gerekir. Paradigmanın birinci tipi elokutif-dil katı seviyesinde, ikinci tipi ise inventif-konseptuel yani kognitif seviyede izlenir. $\mathrm{Bu}$ bakış açısına göre söylemin dil katını öğrenen statik modellerde söylevin (elocution) sentagmatikası da, paradigması da tahlil edilir, dinamik modellerdeyse inventif konseptlerin paradigması ve sentagmatikası tahlil edilir.

\subsection{Baktin'in anlayışında metin ve söylem}

M.Baktin'in ileri sürdüğü gibi "Temiz metin” in çerçevesi dişına çıkan bütün dildışı etkenler büyük ve yaratıcı söz bütününün karışık ve çok planlı sistemini oluşturur. Onlar diskursif sürecin ayrılmaz sıfatları olarak, bu kayanın sualtı kısmı gibi implistit olarak, gizli şekilde metinde mevcuttur. $\mathrm{Bu}$ yüzden onların eksplikatörleri lungvoritorik tahlil zamanı ortaya çıkarılabilir. İntegratif lingvoritorik yaklaşım şimdi dilbilim için otoban olan' 'kaçakçılık" yoludur, fakat yasalaştırılabilir (Bahtin, 1976:122-151 ). 
Fakat belirtmemiz gerekir ki, Bahtin'in düşüncesine göre, dilbilim eserle değil, metinle iş yapar ve eser hakkında onun konuşması "kaçakçılık" yoluyla yapılır ve sadece dilbilim tahlilinden doğmaz. Dil sisteminin ayrı ayrı işaretleri, veya metin(işaretsel bütün olarak) hiç bir zaman ne gerçek, ne yalan, ne güzel olabilir. (Bahtin, 1976: 123). Retorik metnin tüm bu yönlerini gözden geçirir ve kısaca üç nutuk (linqvoretorik) ile ifade eder:

1) Düşünce-nutuk faaliyeti (etos yönü)

2) Düşünce-gerçek (logos yönü)

3) Güzellik-harmoni (pafos yönü)

Lingvoritorik konsepte metin ve söylem gibi söylemin statik ve dinamik yönlerinin kullanılması sayesinde M. M. Bahtin'in söylediği tezdeki ve Fransız göstergebilimci R.Bart'ın bakış açısındakı formalite çelişki ortadan kalkmış olur. R.Bart'a göre "metin prensip olarak edebi esere göre farklılık gösterir: bu estetik bir mahsul değil, işaret faaliyetidir; bu yapı değil yapıyı oluşturan süreçtir; bu pasif nesne değil, işaret ve oyundur; bu anlamı olan içine kapanmış işaretlerin toplusu değil, anlam değişikliklerinin hattının kurulduğu mekandır. Metnin seviyesi anlam değil, bu anlayışın semiotik ve psikoanalitik anlamını belirtendir, gösterendir. $\mathrm{Bu}$ zaman metin geleneksel edebi eser çerçevesinden kenara çıkar: örneğin ' hayat metni' 'ne dönüşür (Bart, 1994: 82)

Fiziksel olarak eseri ve metni ayırmanın istenilen girişimini gereksiz olduğunu vurgulayan R.Bart çeşitli açılarda onları karşılaştırmıştır. (Bart 1994:413 423).

Böylece söylem farklı gerçekliğin çeşitli yönlerini aksettirmek için kullanılan ilk sistemdir, verbal-bilişsel faaliyettir ve 'tarafların öznel tasavvurlarına, onların bir anlık ilgilerine "gerçek" (olgu) veya "'bedii'" yönlerinin hangisinin daha güncel oluşuna bağlıdır”. Çünkü bu sorun metin sürecinde onun karakterini tespit eder ve aynı zamanda onun mahsulü ve amacı olarak ortaya çıkabilir (Mihaylov 2001:108).

Bilgi yüklü metin; kavramaya yani, bu bilginin ortaya çıkarılmasına yönelmiştir. $\mathrm{Bu}$ bakış açısından metnin kendi arhitektonik yapısına ve oluşumuna, burada kullanılmış dil araçlarına v.s göre alıcıda zihinsel model yaratan birimin eser gibi öğrenilmesi gerekir. Metin öyle bir birim ki, metin aracılığıyla, dil ve dünya ile ilgili sıradan bilgilere sahip olan insanlar yeteri kadar doğru sonuçlar ortaya çıkarabilir. $\mathrm{Bu}$ yüzden metin ve söylem tahlili sonuç çıkarmadan, ön bilgi süreçlerine baş vurmadan imkansız olmaktadır. Her bir dil şekli, her şeyden önce 
metin sadece onda mevcut olana değil, aynı zamanda anlamsal sonuca- inferent tipe göre sonuca -hizmet edene işaret ediyor. Metninin 1şınlanma kaynağı bizim bilincimizde çok sayıda etkileşimler ve bilişsel yapıları (sade çerçevelerden daha karışık zihinsel alan ve mümkün alemlere kadar) uyandıran kaynak olarak mevcuttur. Metin bu özelliği sayesinde öyle bir model ki ondan bilgileri toplamak aynı zamanda sonuç çıkarmak ve deneyim edinmek mümkün olabilir.

\section{sunumu.}

3.1. Hipermetin tek çizgide seyretmeyen yazım. Bilginin korunması ve

Metin ve söylem terimleri dışında, bir de bizim hayatımıza giderek daha fazla dahil olan hipermetin fenomeni vardır. Bu kavramla birikte yazılı iletişimimizle ilgili olan izlenimlerimiz tamamen değişiyor. (Визель 1999; Дайсон 1993; Ованесбеков 1993; Семчинская 1997; Субботин 1993; Ворожбикова А.А. 2005, Брейдо 1996).

Dilbilimde hipermetin fikrinin ortaya çıkması daha ziyade internet ağının ortaya çıkmasıyla bağlantılıdır. Hipermetin, metin bilgisinin korunmasının ve sunumunun özel şeklidir. Hipermetnin temel özelliği, çok sayıda sonu olan metinleri mümkün yorumların sonsuzluğu ile seciyelenen bir bütüne çevirmesidir.

Bu fikir ilk defa V. Buş (Rosvelt'in bilim danışmanı) tarafından 1945 yılında öne sürülmüştür. İnsan beyninin çağrışım prensibiyle- yani ana beynin hücrelerindeki her hangi bir düğüme uygun olarak çalışmasına rağmen, bilginin korunmasının ve aranmasının geleneksel olarak alfabe ve rakamlarla yürütüldüğünü biliyoruz. $\mathrm{Bu}$ yüzden de bilginin aranması ve korunmasının alternatif şeklinin bulunması gerektiği düşüncesi ortaya çıkmıyor.

Bu düşünce daha sonra T.Nelson tarafından kullanılır. "Hipermetin" terimi filozof T.Nelson tarafından 1965 yılında daha kısa fragmanlardan olüşan metnin işaretlenmesi için kullanılmıştır. $\mathrm{Bu}$ fragmanlar serbest okunacak şekilde düzenlenmiştir. O zaman, hipermetin "art arta gelmeyen yazıdır" ve burada yapıyı düşünceler oluşturular.

\subsection{Hipermetnin lingvistik kavram sorunu}

Çağdaş devirde bilgisayarların bu alanda uygulanışı tek çizgide seyretmeyen metin fikrini soyut kavramdan metin kurmanın gerçek modeline dönüştürür. Şu anda hipermetin teknolojilerinin geniş kullanımına rağmen, hipermetnin lingvistik kavramını, onun tam anlam karşılığını ortaya koyan kelime yoktur, hatta terimin açıklanışında bile farklı tespitler vardır. Dilbilimde hipermetnin en yaygın tanımı 
Dedova'nın tanımıdır. Dedova hipermetni "yazısız yapılı metin" olarak değerlendirerek şöyle söylüyordu: "tek çizgide seyretmeyen metin", okura bilginin kavranılmasının sırasını seçme şansı verir. Metin, yazarı tatmin etmiyor; çünkü ansiklopedi benzeri geleneksel yayınlar "tek çizgide" okunmamakta, sayfa sayfa okunmaktadir. (Dedova, 2001:22-24).

Hipermetin nedir ve onu geleneksel metinden hangi özellikler ayırır? Bizce hipermetin özellikli yapıya sahiptir ve bu yapıyı elemanların iki tipi oluşturur:

1.Küçük hacimli bağımsız bilgi birimi(fayl, geçit, modül)

2.Diğer bilgi bloğuna geçiş araçlarının mevcutluğu (yollama)

Küçük hacimli bilgi birimlerinin kullanımı ve onların diğer bilgi bloklarına geçişinin mümkünlüğü hipermetnin yapısının kendine özgü şekilde okunuşuna ve bu bilgilerin açık karakterli oluşuna neden olur.

Bunun dışında hipermetin mekanının oluşumunun iki temel özelliğinin de altını çizmek gerekir:

1) Her hangi bir bilginin aynı anda çağrılışı, hipermetnin sıradan yazıyla okunuşunun mümkünlüğü;

2) Başlangıcı ve sonu olmayan hipermetnin yazıyla okunuşunun prensipce imkansız olmasına rağmen okurun yine de her defasında yeni metin oluşturması ve okurun bile hipermetinleri yorumlama imkanlarının sonsuz oluşu.

Şayet ilk halde bütün olan metnin kompozisyon elemanları arasında ilişkiler kuruluyorsa ikinci halde ayrı ayrı oluşturulan metinler arasında bağlar kurulur ve bu durumda okur her hangi bir örneği seçmek zorunda kalır ve böylece okur aynı zamanda yazara dönüşür. "Çünkü bu seçim diologtakı yanıt ile kıyaslanabilir, böylece kendi içinde "kitap" iletişiminin geleneksel teknolojisini taşır" (Dedova, 2001: 25-27).

\section{Değerlendirme ve Sonuç}

Yapılan son çalışmalar kişinin konuşma faaliyeti prensiplerine ve süreçlerine yeniden göz atmayı gerektiriyor. Çünkü dil her zaman sözleri, cümleleri değil metnin fragmanlarını da kullanır. Kavrama ve anlamayı da kelimelere ve cümlelere göre değil metne bağlı olarak gerçekleştirir. Fakat gerçek iletişimde metin dildışı faktorlerin çerçevesinde rol alır yani bilişsel bir boyut kazanır. 
Metin ve söylem birbirinden ayırmak gerekse bile bu kavramlara kesinlikle zıt anlamlar yüklenmemelidir. Bu zıtlık tarafımızca anlamsız bulunmaktadır. Metin aslında anlık (belirli sürecin gerçekleşmesi sonucunda oluşan) yapılanmanın örneğidir ve bu haliyle, sonu olan bir şey gibi öğretilir. Bu da onu söylemden ayırır. Söylemin öğrenimi, onun oluşum süreci ile aynı anda yapılır. Söylem çevrimiçi, cari rejimde, cari zamanda, kendi oluşumu ve gelişimi açısından araştırılan olaydır.

Bilişsel ve dil açısından metin ve söylem anlayışları birbiriyle ilişkililer, her şeyden önce aralarında bir sebep-sonuç ilişkisi bulunmaktadır: metin söylemde yaratılır, onun eseridir. Lakin onlara yaklaşım farklıdır, çünkü söylem hayatı yansıtan faaliyettir. Onu araştırırken olayların tüm sosyal boyutlarını, onun gerçekleştirilmesinin pragmatik faktörlerini dikkate almak önemlidir. Diskursif faaliyeti kültürel ve sosyal -tarihi olaylardan ayrı olarak, diskursif faaliyetin kim tarafından, hangi koşulda, hangi konumda yapıldığı v.s ile ilgili bilgiler olmadan araştırmak imkansızdır. Fakat metni söylenen özelliklerin bir çoğu olmadan da tamamlanmış dil eseri olarak tahlil etmek mümkün. Metin dilbilimciliğinin ortaya çıktığı dönemde söylem ve metnin eş anlamlı terimler olarak kullanılışı da tesadüf değildir.

Hipermetin ise art arta gelmeyen metin şeklidir ve burada düşünceler ve yapılar yaratır, yalnız bu yapılar birbirini takip etmez. Her bir metne has olan hipermetinliğin intermetinlikten fark1; hipermetinde örnekler sistemi yazarın düşüncesinin, niyetinin bir parçasıdır. Hipermetin öne sürülmüş anlamın izahına çaba gösterir, onun bağlantıları nettir. Böylece hipermetin; bilginin (metin ve başka tipli) ifade edilişinin, korunmasının ve sunumunun bir sıra yapı ve fonksiyonel özelliklere sahip olan özel bir aracıdır. Onun metinlerarasılık gibi bir sonunun olmayışı, sonsuz yorum imkanı, bilişim birimleri arasındakı ilişkilerin çağrışımlığ ve rölatiflik(bağlantı) gibi özellikleri vardır.

\section{KAYNAKÇA} Bak1,1999.

Abdullayev, Kamal Mehti oğlu. Azərbaycan dili sintaksisinin nəzəri problemləri.

Бахтин, Михаил Михайлович Проблема текста. Опыт философского анализа// Вопросы литературыю. № 10.- С.122-151 Москва.1976.

Барт, Роланд Избранные работы. Семиотика. Поэтика. - Москва.1994. 
Борботко, Владимир Григоревич . Основная фазового анализа речевой деятельности// Принципы и методы исследования в филологии: Конец XX века. Сб. статей науч.-метод. Семинара «Textus»/- Вып.6/ Под.ред.в-ра филол. наук проф. К.Э.Штайн.-СПб.-Ставрополь . 2001.

Ворожбикова, Александра Анатольевна.Теория текста: антропоцентрическое направление. Москва.2005.

Визель Михаил. Гипертексты по ту и эту сторону экрана// Иностр. литература. № 10. Москва. 1999.

Дайсон, Естер. Порождение смысла из хауса // Вестн.ВИНИТИ .Сер.2-№ 10.-М.. Москва. 1993.

Дедова, Ольга Викторовна. Лингвистическая концепция гипертекста: понятия и терминологическая парадигма// ВМУ Сер.9.Филология. №4 .-С.22-36 Москва. 2001.

Dogan, Günay Metin Bilgisi.Topkap1, İstanbul. 2007.

Купина, Наталя Алексанровна. Тоталитарный язык: словар и речевые реакции.Екатеринбург- Пермь, ЛЕС 1990.Москва. 1995.

Современный русский язык. Анализ языковых единиц.Учеб.пособ. В.3х.ч. Москва. 1995.

Субботин, Мартин Михайлович. Теория и практика нелинейного письма( взгляд сквозь призму « Грамматологии» Ж. Дуррида) // Вопросы философии.- №3.-С.36.; Москва. 1993. 1993.

Тугаева, Зинаида Яковлевна. .Лингвистика текста. Лекции . - СПб., Москва.

Михайская, Анна Константиновна. Основы риторики: Мысль и слово. Учеб. пособие.- Москва. 1996.

Михайлов, Александр Викторович. Слои языковой картины мира// Международная научная конференция «Язык и культура».- Москва. 2001.

Novruzova, Nurida Samet kızı. Mətn sintaksisi. Bakı, 2002.

Zakiyev, Mirfatıx Zakiyeviç Tatar sintaksisı. Kazan,2008. 